\title{
DISPERSÃO E ACUMULAÇÃO DO COBRE NOS PRODUTOS DO INTEMPERISMO DE DEPÓSITOS CUPRÍFEROS DO BRASIL
}

\author{
Jean-Claude PARISOT \\ Monique CREACH \\ Adolpho José MELFI \\ Daniel NAHON \\ Maria Cristina TOLEDO-GROKE \\ Jean Jacques TRESCASES
}

\section{RESUMO}

O estudo geoquímico e mineralógico da alteração supérgena de três zonas cupríferas (Chapada Grande - Goiás; Salobo 3A - Pará e Santa Blandina - São Paulo) permitiu caracterizar o comportamento do cobre nos perfis de alteração desenvolvidos em zonas lateríticas. Este estudo mostrou que a mobilidade ou fixação do cobre depende, essencialmente, da natureza e da quantidade das fases supérgenas neoformadas e da natureza das soluções de alteração. Em Chapada Grande, a goethita é a principal fase fixadora de cobre no manto de intemperismo e as soluções percolantes são pobres em cobre. Assim, como a goethita é pouco abundante no perfil e como sua capacidade de fixar cobre é limitada, este elemento é quase que totalmente lixiviado da zona de alteração. Em Salobo 3A, são as vermiculitas, os interestratificados biotita-vermiculita e as goethitas que constituem as principais fases fixadoras de cobre mostrando que as soluções percolantes são ligeiramente mais ricas neste elemento. Nessas condições, levando-se em conta o alto poder de fixação dos filossilicatos e os teores elevados de goethita no perfil, o essencial do estoque de cobre do minério primário é conservado no manto de alteração. Em Santa Blandina, condições particulares promovem a formação, na base dos perfis, de silicatos específicos de $\mathrm{Cu}$ (crisocola) a partir da existência de soluções muito ricas em cobre. Neste contexto o cobre se acumula na base do manto de intemperismo.

\section{ABSTRACT}

Geochemical and mineralogical studies carried out on weathered material at three cupriferous deposits (Chapada Grande - Goiás, Salobo 3A - Pará and Santa Blandina - São Paulo) led to verify copper behavior in lateritic weathering profiles. It has been showed that copper retention or mobilization depends on the nature and variety of supergene neoformed phases and on the nature of weathering solutions. In Chapada Grande, goethite is the main secondary phase able to retain copper in weathered mantle, percolating solutions are copper depleted. So, as goethite is not abondant and as its capacity to retain copper is limited, copper is almost totally removed from the weathered material. In Salobo 3A, vermiculite, interestratified biotite-vermiculite and goethite are the main secondary phases that retain copper, and percolating solutions are little richer in copper. So, as phyllosilicates can retain much copper and as there is high contents on goethite through the profile, much of primary copper is fixed on weathered mantle. In Santa Blandina, peculiar conditions lead to very rich copper solutions and to copper silicate (chrysocola) formation at the bottom of the profile. So, copper is accumulated at the bottom of weathered mantle. 


\section{INTRODUÇÃO}

O comportamento geoquímico do cobre durante a alteração supérgena tem sido objeto de inúmeros estudos, que concernem, essencialmente, a prospecção geoquímica (CHAFFE, 1975; DAVY, 1979; WARNANT et al., 1981; GOVET, 1987; PARISOT et al., 1983), os minerais secundários específicos de cobre, como por exemplo os sulfetos de cementação (SERKIES et al., 1966; SILLITOE \& CLARK, 1969; THORNBER, 1979, 1985) ou os óxidos, silicatos e carbonatos (NEWBERG, 1967; GASTUCHE VAN OOSTERWYCK, 1970, 1977; NICKEL, 1982, 1984; KOUD, 1985; WOODS \& GARRELS, 1986), ou ainda os minerais susceptiveis de fixarem o cobre, tais como cloritas (BANKS, 1974; MCBRIDE, 1976; NOTEBAART, 1978), vermiculitas (BASSET, 1958; ILDEFONSE et al., 1986), esmectitas (MCLAREN et al., 1983; HARSH \& DONER, 1984; MOSSER et al., 1989), caolinitas (MOSSER \& ZEEGERS, 1988) e óxidos de ferro (NOWLAN, 1976; LAVILLE-TIMSIT et al., 1976; LEARNED et al., 1981; VEIGA \& SCHORSCHER, 1982).

Entretanto, estudos que focalizam o comportamento do cobre no seio de perfis lateríticos são bem menos freqüentes (NICKEL, 1984; KOUD, 1985; TOLEDO-GROKE, 1986; CREACH, 1988; PARISOT, 1989), apesar da evidente importância que apresentam tanto no tocante à determinação dos mecanismos que regem este comportamento, como no que diz respeito aos ensinamentos práticos, referentes à sua prospecção e exploração.

No Brasil, onde a maior parte das zonas mineralizadas em cobre encontra-se recoberta por espessos mantos de alteração laterítica, o estudo de seu comportamento geoquímico no decorrer do processo intempérico pode contribuir de forma decisiva para a valorização deste bem mineral.

A fim de estudar o comportamento do cobre durante a alteração laterítica, três zonas mineralizadas foram selecionadas (Figura 1). Nos perfis de alteração destas três zonas, o cobre apresenta um comportamento totalmente diferenciado: em Chapada Grande, ele é progressivamente lixiviado da base para o topo do perfil; em Santa Blandina, minerais secundários específicos de cobre se acumulam em certas fácies dos produtos de alteração e promovem sua acumulação no manto de intemperismo e, finalmente, no Salobo 3A, o saprolito apresenta teores em cobre comparáveis àqueles encontrados no minério primário, sem que nenhum mineral específico de cobre tenha sido identificado (exceção feita às raras malaquitas encontradas, essencialmente na base do perfil). Neste depósito, o saprolito pode ser considerado como um minério potencial do tipo oxidado.

Assim, com o objetivo de definir os fatores que determinaram estas diferenças de comportamento, as três zonas mineralizadas foram estudadas geoquimicamente, a partir de uma amostragem completa e sistemática de todas as fácies de alteração, desde a rocha fresca até as mais alteradas.

As análises geoquímicas, conduzidas por espectrometria de absorção atômica, métodos gravimétricos e colorimetria, foram realizadas sobre amostras totais, e sobre algumas frações granulométricas superiores a $2 \mu \mathrm{m}$. Foram igualmente dosadas por absorção atômica as soluções provenientes das extrações seletivas dos óxidos de ferro pelo reativo de Tamm, aplicado sob radiação ultravioleta (DE ENDREDY, 1963), bem como as soluções obtidas após saturação por $\mathrm{BaCl}_{2}$ (bases trocáveis). Paralelamente, um estudo petrológico e mineralógico foi realizado, utilizando-se mcroscopia óptica, microscopia eletrônica de varredura, difração de Raios-X e microanálises por sonda eletrônica.

\section{OS DEPÓSITOS CUPRÍFEROS ESTUDADOS}

\subsection{Chapada Grande}

Situada a $250 \mathrm{~km}$ a noroeste de Brasília, a mineralização cuprífera de Chapada Grande encontra-se associada a seqüências metassedimentares de idade proterozóica (FUCK \& MARINI, 1979).

Na zona mineralizada, platôs encouraçados, com topos situados 20 a $30 \mathrm{~m}$ acima da rede de drenagem atual, representam relíquias do entalhamento de uma antiga superfície de aplainamento pleistocênica (BRAUN, 1970). Atualmente, a região encontra-se submetida a um clima tropical úmido, com estações contrastantes. Cerca de $80 \%$ dos $1.800 \mathrm{~mm}$ anuais de chuvas ocorre entre dezembro e fevereiro. Uma estação seca, bem marcada, vai de junho a setembro. A temperatura média anual é de $23^{\circ} \mathrm{C}$.

A rocha fresca mineralizada (RF) é um micaxisto constituído por proporções variáveis de quartzo, flogopita, plagioclásios, anfibólios, moscovita, paragonita, distênio e calcita. Na região, esta rocha encontra-se recoberta por um espesso manto de alteração, que ultrapassa $50 \mathrm{~m}$ de espessura. Nos perfis de planalto, seis horizontes de alteração, cujja evolução mineralógica encontra-se esquematizadia na Figura 2, são descritos da base para o topo: 


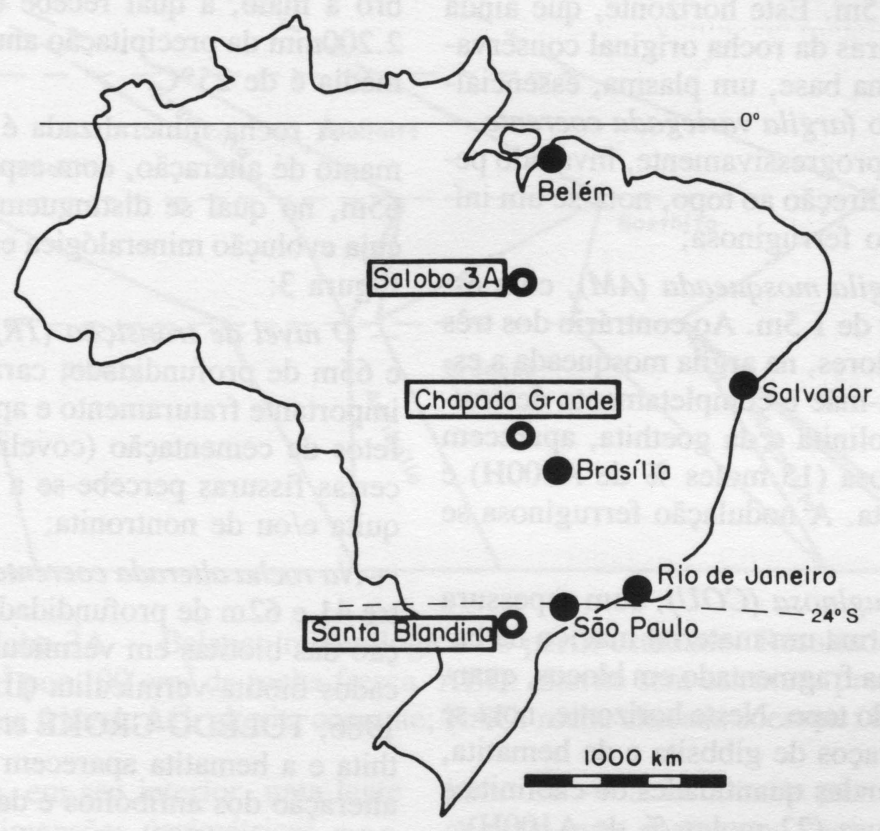

FIGURA 1 - Mapa de localização das áreas estudadas.

- Rocha alterada coerente (RAC), com espessura entre 15 e $20 \mathrm{~m}$. Neste horizonte, que conserva as estruturas primárias, a alteração progride a partir de diaclases e fraturas, dando origem a um material arenizado friável. Um plasma, essencialmente esmectítico, com traços de caolinita e de vermiculita, se desenvolve a partir dos minerais primários;
- Horizonte - cinza-esverdeado (HCV), com espessura total entre 7 e $10 \mathrm{~m}$. Com estruturas primárias preservadas, este horizonte caracteriza-se pelo desenvolvimento de caolinita, que se encontra associada a pequenas quantidades de esmectita, no interior de um plasma argiloso, ou isolada nas pseudomorfoses das micas brancas, que são os últimos minerais primários da rocha a serem alterados;

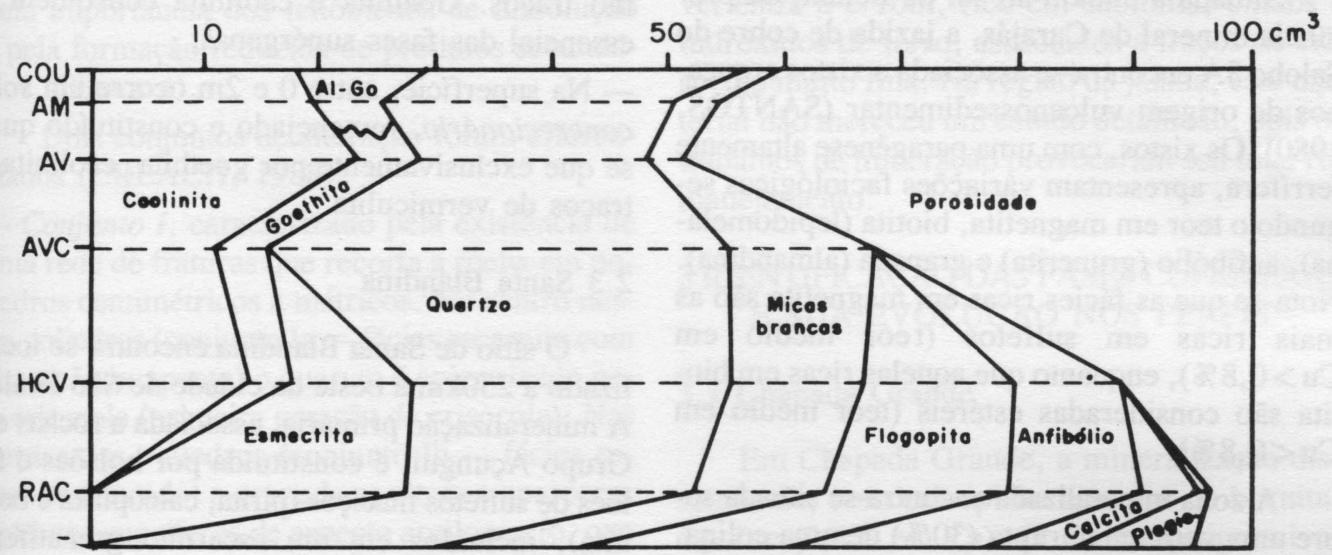

FIGURA 2 - Chapada Grande: Balanço mineralógico do perfil estudado. Resultados expressos em $\mathrm{cm}^{3}$ por $100 \mathrm{~cm}^{3}$ de rocha fresca. COU: couraça; AM: argila mosqueada; AV: argila variegada; AVC: argila variegada coerente; HCV: horizonte cinza-esverdeado; RAC: rocha alterada coerente; $\mathbf{R F}$ : rocha fresca. 
- Horizonte argila variegada $(A V)$, com espessura média de $15 \mathrm{~m}$. Este horizonte, que ainda possui as estruturas da rocha original conservadas, apresenta, na base, um plasma, essencialmente caolinítico (argila variegada coerente $A V C$ ), o qual é, progressivamente, invadido pela goethita. Em direção ao topo, nota-se um início de nodulação ferruginosa;

- Horizonte argila mosqueada (AM), com espessura ao redor de $1,5 \mathrm{~m}$. Ao contrário dos três horizontes anteriores, na argila mosqueada a estrutura da rocha-mãe é completamente destruída. Além da caolinita e da goethita, aparecem goethita aluminosa ( 15 moles $\%$ de $\mathrm{A} 100 \mathrm{H})$ e traços de gibbsita. A nodulação ferruginosa se acentua;

- Couraça ferruginosa (COU), com espessura de 0 a $1,5 \mathrm{~m}$. Forma um material maciço na base, o qual se torna fragmentado em blocos, quando se aproxima do topo. Neste horizonte, nota-se a presença de traços de gibbsita e de hematita, associadas a grandes quantidades de caolinita $\mathrm{e}$ goethita aluminosa (22 moles \% de $\mathrm{A} 100 \mathrm{H}$ );

A presença, em um dos perfis estudados, de um filão de quartzo que atravessa, sem perturbação aparente, estes dois últimos horizontes, permite supor que o volume inicial da rocha é pouco ou mesmo não modificado, apesar da estrutura da rocha original não ser mais detectável.

Um solo, com cerca de $0,3 \mathrm{~m}$ de espessura, recobre esses horizontes. Trata-se de um solo rico em nódulos e cascalhos ferruginosos, que apresentam diâmetros entre 0,5 e $3 \mathrm{~cm}$, e que foram herdados da couraça.

\subsection{Salobo 3A}

Situada a $550 \mathrm{~km}$ ao sul de Belém, na província mineral de Carajás, a jazida de cobre do Salobo 3A encontra-se associada a xistos arqueanos de origem vulcanossedimentar (SANTOS, 1980). Os xistos, com uma paragênese altamente ferrífera, apresentam variações faciológicas segundo o teor em magnetita, biotita (lepidomelana), anfibólio (grunerita) e granada (almandina). Nota-se que as fácies ricas em magnetita são as mais ricas em sulfetos (teor médio em $\mathrm{Cu}>0,8 \%$ ), enquanto que aquelas ricas em biotita são consideradas estéreis (teor médio em $\mathrm{Cu}<0,8 \%)$.

A zona mineralizada encontra-se situada sobre uma vertente abrupta (30\%) de uma colina. Os planos de xistosidade apresentam mergulhos subverticais para NE a SW, e são perpendiculares à direção da inclinação topográfica.

O clima da região é caracterizado pela alternância de uma estação seca, que vai de junho a outubro, e de uma estação úmida, de novembro a maio, a qual recebe cerca de $90 \%$ dos $2.200 \mathrm{~mm}$ da precipitação anual. A temperatura média é de $25^{\circ} \mathrm{C}$.

A rocha mineralizada é recoberta por um manto de alteração, com espessura ao redor de $65 \mathrm{~m}$, no qual se distinguem cinco horizontes, cuja evolução mineralógica está representada na Figura 3:

- O nível de transição (TR), situado entre 62 e $65 \mathrm{~m}$ de profundidade, caracteriza-se por um importante fraturamento e aparecimento de sulfetos de cementação (covelita e digenita). Em certas fissuras percebe-se a presença de malaquita e/ou de nontronita;

- Na rocha alterada coerente $(R A C)$, situada entre 41 e $62 \mathrm{~m}$ de profundidade, nota-se a alteração das biotitas em vermiculita e interestratificados biotita-vermiculita (ILDEFONSE et al., 1986; TOLEDO-GROKE et al., 1990). A goethita e a hematita aparecem como produtos da alteração dos anfibólios e das granadas (PARISOT et al., 1983);

- O saprolito apresenta dois sub-horizontes bem diferenciados: alterita coerente $(A C)$, situada entre 16 e $41 \mathrm{~m}$ de profundidade, e alterita-friável $(A F)$, entre 6 e $16 \mathrm{~m}$ de profundidade, o qual se caracteriza pelo aumento da proporção de vermiculita e interestratificados biotita-vermiculita e o aparecimento de esmectita e de caolinita. A goethita torna-se a principal fase ferrífera. A proporção de caolinita aumenta em direção ao topo do horizonte em detrimento da esmectita e dos interestratificados;

- Na alterita sem estrutura da rocha original preservada (AED), de 2 a $6 \mathrm{~m}$, a esmectita desaparece totalmente e a vermiculita permanece como traços. Goethita e caolinita constituem o essencial das fases supérgenas;

- Na_superfície, entre 0 e $2 \mathrm{~m}$ ocorre um solo concrecionário, remanejado e constituído quase que exclusivamente por goethita, caolinita e traços de vermiculita.

\subsection{Santa Blandina}

O sítio de Santa Blandina encontra-se localizado a $250 \mathrm{~km}$ a oeste da cidade de São Paulo. A mineralização primária, associada a rochas do Grupo Açungui, é constituída por bolsões e filões de sulfetos maciços (pirita, calcopirita e bornita), incluídos em um escarnito granatífero (grossulária-andradita). O escarnito, que se apresenta como um corpo alongado de $400 \mathrm{~m}$ de comprimento por $150 \mathrm{~m}$ de largura, é formado de uma fácies rica em granada $(67,3 \%$ de grossuláriaandradita, $16,3 \%$ de quartzo e $16 \%$ de diopsí- 
10

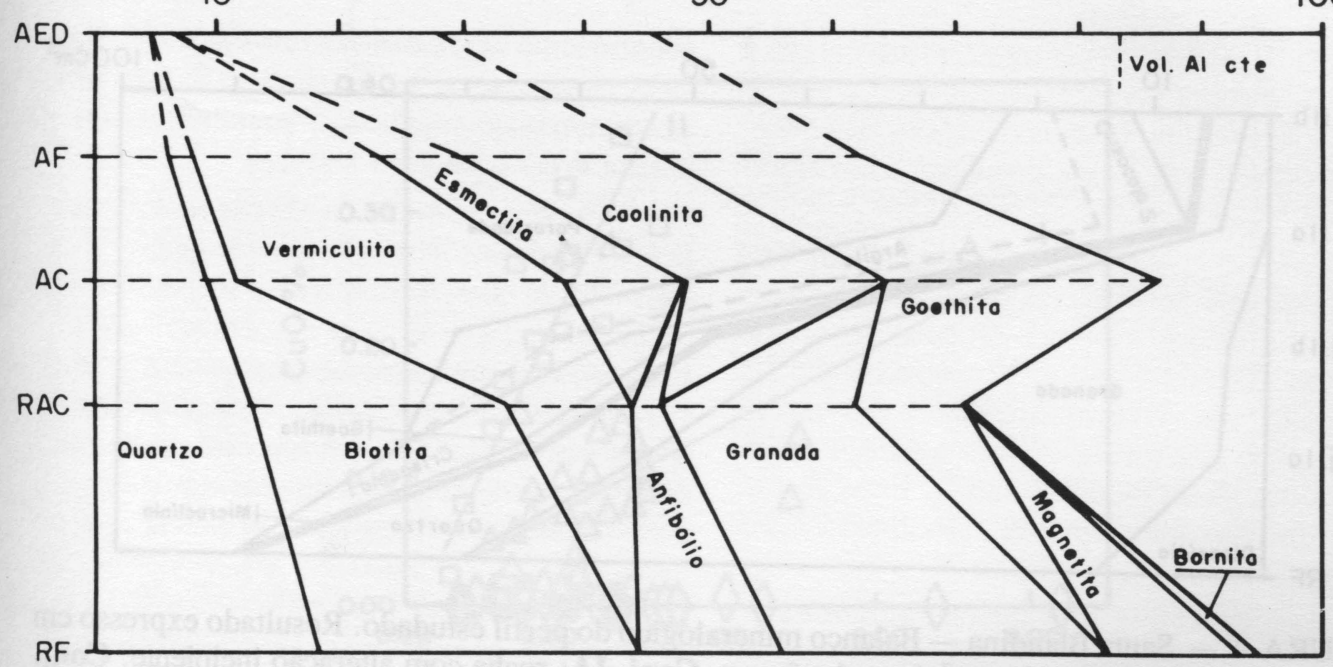

FIGURA 3 - Salobo 3A - Balanço mineralógico do perfil estudado. Resultados expressos em $\mathrm{cm}^{3}$ por $100 \mathrm{~cm}^{3}$ da rocha fresca. AED: alterita sem estrutura preservada; AF: alterita friável; AC: alterita coerente; RAC: rocha alterada coerente; RF: rocha fresca.

dio), apresentando, em seu interior, uma lente de mármore, de dimensões ảecimétricas.

A região encontra-se sob a influência de um clima tropical úmido. As precipitações anuais médias variam de 1.550 a $2.000 \mathrm{~mm}$ e as temperaturas de 18 a $20^{\circ} \mathrm{C}$.

Durante a alteração, a dissolução do mármore leva à formação de cavidades cársticas, que podem ser preenchidas por produtos formados na alteração do escarnito. Os bolsões e os filões de sulfetos maciços dão origem a "chapéus de ferro".

As principais etapas de alteração dos escarnitos granatíferos podem ser acompanhadas na base da mina a céu aberto, até nas proximidades da cavidade cárstica. A alteração se caracteriza pela importância dos fenômenos de dissolução e pela formação reduzida de produtos secundários (Figura 4).

Dois conjuntos de alteração foram diferenciados (CREACH, 1988):

- Conjunto I, caracterizado pela existência de uma rede de fraturas que recorta a rocha em poliedros centimétricos a métricos. No centro destes poliedros (conjunto Ia - fácies escarnito com alteração incipente) o quartzo é epigenizado pela crisocola (primeira geração de crisocola). Nas bordas dos poliedros (conjunto $\mathrm{Ib}$ - fácies escarnito alterado) a granada se altera e aparecem produtos cupríferos de aspecto argilomorfo, que epigenizam quartzo e granadas.

- No conjunto II, os fenômenos de dissolução se acentuam, levando à formação de uma fácies altamente porosa (a porosidade pode ultrapassar $75 \%$ ), com estrutura da rocha conservada (con- junto IIa - fácies alterita porosa). A crisocola que não mais aparece no conjunto IIa, onde somente os produtos argilomorfos estão presentes, reaparece no conjunto IIb (fácies alterita porosa, lixiviada), formando uma segunda geração de crisocola.

Em direção à superfície, caolinita e goethita se individualizam, enquanto que as proporções de crisocola e produtos argilomorfos cupríferos (esmectita, interestratificados esmectita-caolinita em íntima associação com crisocola muito fina) diminuem.

Por se tratar de um relevo cárstico, estes conjuntos de alteração podem ser encontrados até a superfície do terreno, ou podem estar recobertos por um solo laterítico, com espessura variável entre 0 e $10 \mathrm{~m}$, rico em caolinita, óxidos e hidróxidos de ferro, associados a traços de crisocola muito fina. Na região da jazida, este material não mereceu um estudo detalhado, pois os trabalhos de mineração provocaram seu total remanejamento.

\section{IDENTIFICAÇÃO DAS FASES CUPRÍFERAS E SUA EVOLUÇÃO NOS PERFIS}

\subsection{Chapada Grande}

Em Chapada Grande, a mineralização disseminada, com calcopirita e traços de bornita, é pobre $(0,4 \% \mathrm{em} \mathrm{Cu})$. $\mathrm{O}$ cobre é progressivamente lixiviado da base para o topo do perfil. Esta lixiviação é particularmente importante nos horizontes superficiais (argila variegada, argila mosqueada e couraça), onde somente $10 \%$ do conteúdo inicial em cobre permanece (Tabela 1). 


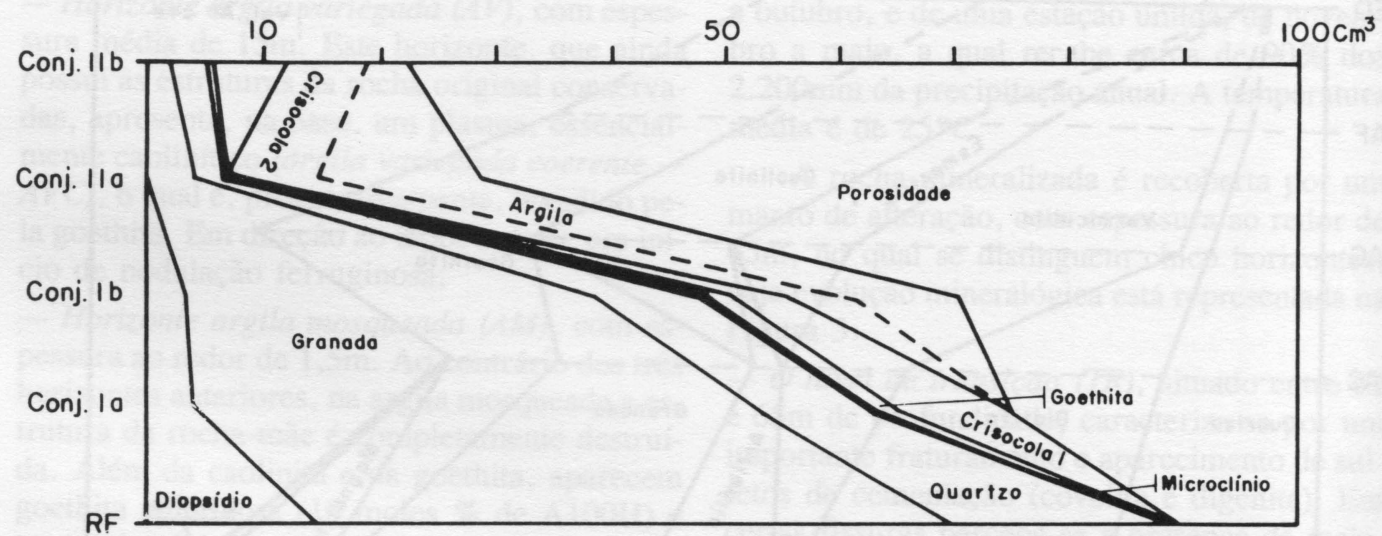

FIGURA 4 - Santa Blandina - Balanço mineralógico do perfil estudado. Resultado expresso em $\mathrm{cm}^{3}$ por $100 \mathrm{~cm}^{3}$ da rocha fresca. Conj. IA: rocha com alteração incipiente; Conj. Ib: rocha alterada; Conj. IIa: alterita porosa; Conj. IIb: alterita porosa lixiviada.

Nestes horizontes nenhum mineral específico deste elemento foi identificado.

$\mathrm{Na}$ base do perfil de alteração, no horizonte rocha alterada coerente, a calcopirita é afetada por fenômenos de dissolução. Uma parte do cobre liberado (aproximadamente $8 \%$ ) se distribui de maneira aleatória no plasma de alteração esmectítico de todos os minerais. $\mathrm{O}$ teor médio deste plasma é entretanto baixo $(0,06 \%$ em $\mathrm{CuO})$ e o cobre não apresenta correlação com nenhum elemento. Entretanto, dois grupos de pontos apresentam uma correlação $\mathrm{Fe}-\mathrm{Cu}$ significativa no limiar de $1 \%$ (Figura 5). No primeiro grupo (I) nota-se um coeficiente de correlação $\mathrm{Fe}-\mathrm{Cu}$ de 0,53 , mas igualmente $\mathrm{Na}-\mathrm{Cu}(\mathrm{r}=0,77)$ e Ti$\mathrm{Cu}(\mathrm{r}=0,56)$. Este grupo pode ser interpretado como uma fase micácea (flogopita) alterada em vermiculita e depois em esmectita. No segundo grupo (II), somente a correlação $\mathrm{Fe}-\mathrm{Cu}(\mathrm{r}=0,82)$ aparece. A esmectita, que representa $23 \%$ da rocha alterada coerente (RAC), contém portanto $3 \%$ do $\mathrm{CuO}$ do horizonte; $97 \%$ do $\mathrm{CuO}$ encontra-se ainda sob a forma de calcopirita.

\begin{tabular}{|c|ccc|}
\hline & 1 & 2 & 3 \\
\hline COU & 0,11 & 0,08 & $-87,90$ \\
AM & 0,12 & 0,07 & $-88,80$ \\
AV & 0,15 & 0,08 & $-87,60$ \\
AVC & 0,25 & 0,16 & $-75,00$ \\
HCV & 0,34 & 0,29 & $-55,80$ \\
RAC & 0,49 & 0,45 & $-31,20$ \\
RF & 0,65 & 0,65 & - \\
\hline
\end{tabular}

TABELA 1 - Balanço geoquímico do cobre no manto de alteração da área mineralizada de Chapada Grande: 1 = teor em $\mathrm{CuO}$ em $\%$ peso; 2 $=$ teor $\mathrm{em} \mathrm{CuO} \mathrm{em} \mathrm{g}$ por $100 \mathrm{~g}$ de rocha fresca; $3=\%$ de perdas de $\mathrm{CuO}$ em relação à rocha fresca. Os valores das colunas 2 e 3 foram cal- culados a volume constante. COU: couraça; AM: argila mosqueada; AV: argila variegada; AVC: argila variegada coerente; HCV: horizonte cinza-esverdeado; RAC: rocha alterada coerente; RF: rocha fresca.

Entre as microanálises dos produtos de alteração do horizonte cinza-esverdeado, somente a correlação $\mathrm{Fe}-\mathrm{Cu}(\mathrm{r}=0,46)$ é significativa no limiar de $1 \%$. Neste horizonte a calcopirita é ainda abundante e os cálculos de balanço geoquímico permitem estimar que este sulfeto contém $85 \%$ do $\mathrm{CuO}$ do horizonte.

Nos horizontes superficiais, as frações $<2 \mu \mathrm{m}$ foram submetidas a extrações seletivas de óxidos de ferro, utilizando-se o reativo de Tamm sob UV. Este ataque afeta sobretudo a goethita, que é o principal óxido de ferro identificado, mas igualmente uma pequena quantidade de caolinita. Qualquer que seja o horizonte, as curvas cumulativas de extração do ferro e do cobre são similares, indicando uma associação entre estes dois elementos (Figura 6).

Tanto na argila variegada como na argila mosqueada, o essencial do cobre (respectivamente 74 e $86 \%$ ) é extraído juntamente com o ferro. As análises efetuadas por sonda eletrônica mostram efetivamente uma boa correlação $\mathrm{Fe}-\mathrm{Cu}$ na argila variegada $(r=0,87)$; entretanto, esta correlação desaparece na argila mosqueada. Realmente, neste horizonte, a distribuição do cobre, no plasma de alteração torna-se aleatória e notase o aparecimento de óxidos de ferro onde o cobre está ausente e isto independentemente de sua taxa de substituição em alumínio. Nestes horizontes a goethita é a principal fase ferrífera.

$\mathrm{Na}$ couraça, as microanálises mostram igualmente uma distribuição aleatória do cobre, como foi visto para a argila mosqueada, com a existência de óxidos de ferro sem cobre, mas igualmente a presença de concentrações em $\mathrm{CuO}$ $(0,1$ a $0,3 \%)$ nos plasmas pouco ferruginosos $(2$ a 5\% de Fe203). Estes teores em $\mathrm{CuO}$ são com- 


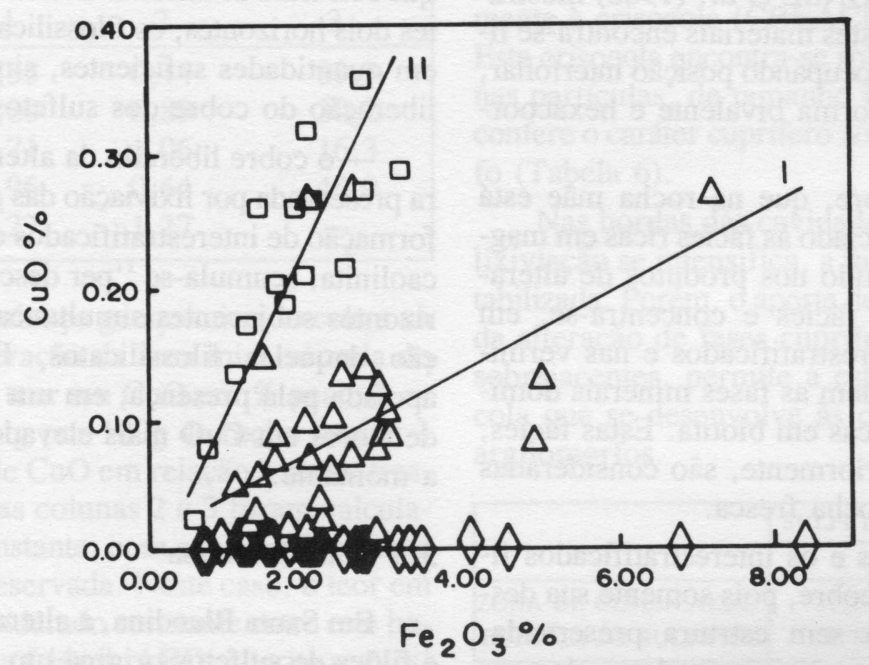

FIGURA 5 - Correlação $\mathrm{Fe}_{2} \mathrm{O}_{3}-\mathrm{CuO}$ no horizonte rocha alterada coerente (RAC) do perfil de Chapada Grande. I $\Delta(\mathrm{R}=0,53)$; II Ó $(\mathrm{R}=0,82)$.

paráveis àqueles dosados nas goethitas "cupríferas".

Durante o ataque seletivo, somente $45 \%$ do $\mathrm{CuO}$ do horizonte é extraído com os óxidos de ferro. Admitindo que o cobre não extraído encontra-se associado ao ferro restante, obtémse uma fase ferrífera com $4 \% \mathrm{CuO}$, o que não foi jamais observado. Portanto, somos obrigados a pensar na existência, na couraça, de uma fase cuprífera independente dos óxidos de ferro. Na couraça e na argila mosqueada, observase então uma dissociação parcial entre o cobre e o ferro. Por outro lado, nota-se que os teores médios em $\mathrm{CuO}$ das goethitas "cupríferas" são mais baixos na couraça $(0,3 \%)$ que nas argilas variegadas $(1 \%)$.

As análises por ressonância paramagnética eletrônica e microscopia eletrônica de transmissão de frações $<2 \mu \mathrm{m}$ deferrificadas de amostras da couraça indicam a presença de cobre em posição octaédrica no retículo de caolinitas (MOSSER et al., 1989). Portanto, na couraça, parece que uma parte do cobre associada às goethitas é liberada e integra o retículo de caolinitas que se formam neste horizonte.

\subsection{Salobo $3 \mathrm{~A}$}

Somente a rocha alterada coerente, que ocorre na base do perfil, e sobretudo a alterita sem estrutura da rocha preservada, que aparece no topo, apresentam perdas significativas em cobre, em relação à rocha inicial (Tabela 2). Os raros minerais específicos de cobre (malaquita, cuprita), presentes nos horizontes com estrutura da rocha conservada, não podem explicar a existência de teores em cobre comparáveis àqueles da rocha fresca.

No topo da rocha fresca e no horizonte de transição, sulfetos de cementação (covelita, calcosita, digenita) são identificados como produtos de transformação da calcopirita e da bornita. Este último mineral, cuja proporção aumenta em direção ao topo da rocha fresca, poderia, igualmente, ser em parte de origem supérgena. Notase neste nível a presença esporádica de malaquita nas fissuras.

Nos horizontes sobrejacentes, os minerais específicos de cobre desaparecem completamente e quatro fases portadoras deste elemento foram identificadas (TOLEDO-GROKE et al., 1985):

- Os óxidos de manganês, mesmo apresentando, por vezes, teores em $\mathrm{CuO}$ relativamente elevados ( 3 a $25 \%$ ), constituem sempre uma fase cuprífera acessória;

- As esmectitas, que apresentam teores médios de cerca de $1,5 \%$ em $\mathrm{CuO}$, possuem $6 \%$ do total de cobre do saprolito (Tabela 3);

- As goethitas, cujos teores médios em $\mathrm{CuO}$ variam de 1 a $2 \%$, possuem de 12 a $20 \%$ de $\mathrm{CuO}$ total dos horizontes com estruturas da rocha original conservadas (saprolito e rocha alterada coerente) e $64 \%$ do $\mathrm{CuO}$ existente na alterita sem estrutura preservada (Tabela 3). Nota-se que a goethita é muito mais abundante neste depósito do que em Chapada;

- As vermiculitas e os interestratificados biotita-vermiculita, com teores médios em $\mathrm{CuO}$ de 6 a $8 \%$, possuem 70 a $80 \%$ do $\mathrm{CuO}$ dos horizontes com estrutura conservada e $35 \%$ do cobre total dos horizontes sem estrutura preservada 
(Tabela 3). ILDEFONSE et al. (1986) mostraram que o cobre nestes materiais encontra-se ligado à vermiculita, ocupando posição interfoliar, não trocável, sob forma bivalente e hexacoordenado.

Portanto o cobre, que na rocha mãe está principalmente associado às fácies ricas em magnetitas, é redistribuído nos produtos de alteração das diferentes fácies e concentra-se, em particular, nos interestratificados e nas vermiculitas, que constituem as fases minerais dominantes das fácies ricas em biotita. Estas fácies, como foi dito anteriormente, são consideradas como estéreis na rocha fresca.

As vermiculitas e os interestratificados fixam eficazmente o cobre, pois somente sua destruição, na alterita sem estrtura preservada, permite a liberação e a lixiviação desse elemento. Na rocha alterada coerente, apesar de todos os sulfetos já se apresentarem alterados, a baixa quantidade de vermiculita e interestratificados provoca uma perda em cobre, notadamente em relação aos dois horizontes sobrejacentes (Tabela 2). Duas hipóteses podem ser formuladas:

- a rocha alterada coerente está, atualmente, submetida a uma alteração diferente daquela que sofreram as alteritas coerente e friável. Nestes dois horizontes, os filossilicatos se formaram em quantidades suficientes, simultaneamente à liberação do cobre dos sulfetos;

- o cobre liberado da alterita sem estrutura preservada por lixiviação das goethitas e transformação de interestratificados e vermiculita em caolinita, acumula-se "per descensum" nos horizontes subjacentes simultaneamente à formação daqueles filossilicatos. Esta hipótese é apoiada pela presença, em um dado horizonte, de teores em $\mathrm{CuO}$ mais elevados a jusante que a montante.

\subsection{Santa Blandina}

Em Santa Blandina, a alteração dos bolsões e filões de sulfetos origina um chapéu de ferro e acumulação de sulfetos secundários que retêm a maior parte do cobre (cerca de $60 \%$ ), e libera uma parcela deste cobre que se vai acumular na base do perfil, nas diferentes fácies (conjuntos I e II) de alteração do escarnito granatífero (Tabelas 4 e 5 ).

Diversos casos podem então ser observados (CREACH, 1988):
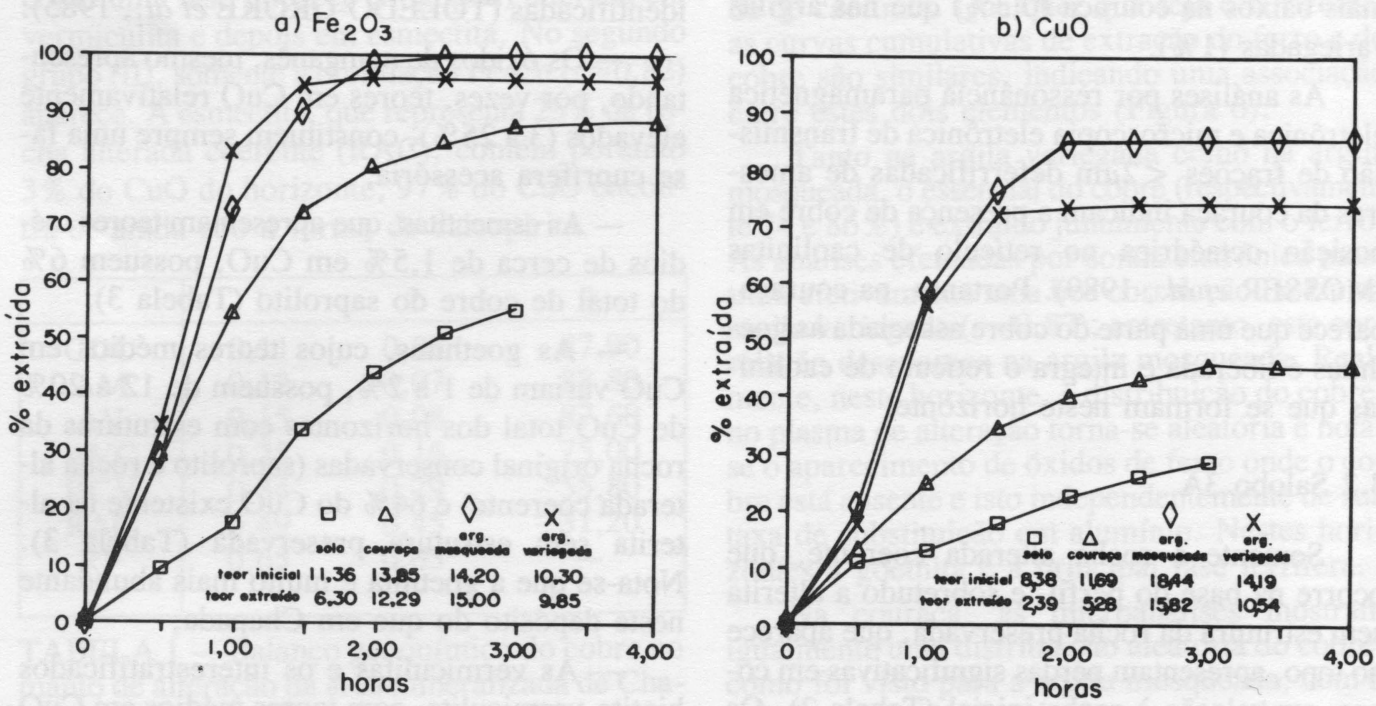

FIGURA 6 - Curvas cumulativas do $\mathrm{Fe}_{2} \mathrm{O}_{3}$ e do CuO, extraídos pelo reativo oxálico, sob radiação ultravioleta, para os materiais de Chapada Grande. $100 \%=$ total de elementos na fração $<2 \mu \mathrm{m}$. 


\begin{tabular}{|c|ccc|}
\hline & 1 & 2 & 3 \\
\hline AED & 0,35 & 0,14 & $-89,3$ \\
AF & 1,89 & 0,89 & $-30,2$ \\
AC & 1,71 & 1,06 & $-16,3$ \\
RAC & 0,96 & 0,64 & $-49,9$ \\
RF & 1,27 & 1,27 & - \\
\hline
\end{tabular}

TABELA 2-Balanço geoquímico do cobre na cobertura de alteração da área mineralizada do Salobo 3A: 1 = teor em $\mathrm{CuO}$ em $\%$ peso; $2=$ teor em $\mathrm{CuO}$ em g por $100 \mathrm{~g}$ de rocha fresca; 3 $=\%$ de perdas de $\mathrm{CuO}$ em relação à rocha fresca. Os valores das colunas 2 e 3 foram calculados a volume constante, com exceção da alterita sem estrutura preservada. Neste caso, o teor em alumínio foi considerado constante entre este horizonte e a alterita friável. AED: alterita sem estrutura preservada; AF: alterita friável; AC: alterita coerente; RAC: rocha alterada coerente; RF: rocha fresca.

\begin{tabular}{|c|ccc|ccc|ccc|}
\hline & \multicolumn{3}{|c|}{ GOETHITA } & \multicolumn{3}{|c|}{ VERMICULITA } & \multicolumn{3}{c|}{ ESMECTITA } \\
\hline & 1 & 2 & 3 & 1 & 2 & 3 & 1 & 2 & 3 \\
\hline AED & 42,20 & 0,80 & 64,20 & 2,90 & 6,70 & 35,80 & & & \\
\hline AF & 24,80 & 1,80 & 23,00 & 20,70 & 6,70 & 70,90 & 7,80 & 1,50 & 6,10 \\
\hline AC & 19,20 & 1,80 & 15,10 & 27,30 & 6,70 & 78,90 & 9,20 & 1,50 & 6,00 \\
\hline RAC & 13,00 & 0,90 & 12,60 & 9,70 & 8,60 & 87,40 & & & \\
\hline
\end{tabular}

TABELA 3 - Distribuição do cobre nos diferentes minerais neoformados na cobertura de alteração do Salobo 3A: $1=\mathrm{g}$ do mineral por $100 \mathrm{~g}$ de amostra do horizonte; $2=$ teor médio em $\mathrm{CuO}(\%)$ em cada mineral; $3=\%$ de $\mathrm{CuO}$ em relação ao $\mathrm{CuO}$ total do horizonte. AED: alterita sem estrutura preservada; AF: alterita friável; AC: alterita coerente; RAC: rocha alterada coerente.

- nas fissuras da rocha, quando ainda nenhum mineral primário encontra-se alterado, o cobre liberado pela alteração dos bolsões de sulfetos precipita sob a forma de malaquita;

- por ocasião da alteração do escarnito, o quartzo se altera em primeiro lugar, e as concentrações em sílica e em cobre nas soluções de alteração são suficientemente elevadas, permitindo a formação de crisocola, que epigeniza o quartzo;

- por sua vez, quando a granada se altera, o alumínio e a sílica liberados, além do cobre proveniente da alteração dos sulfetos, permitem a formação de produtos cupríferos de aspecto argilomorfo, que epigenizam o quartzo e as granadas. Um estudo cristaloquímico destes produtos argilomorfos mostra que eles são constituídos de uma fase argilosa, composta de esmectita e de interestratificado esmectita-caolinita, desprovidas de cobre, a qual se associa intimamente à crisocola (CREACH et al., no prelo). Esta crisocola encontra-se sob a forma de pequenas partículas, de tamanho inferior a $0,5 \mu \mathrm{m}$, e confere o caráter cuprífero ao produto argilomorfo (Tabela 6).

Nas bordas das cavidades cársticas, onde a lixiviação se intensifica, a fase argilosa é desestabilizada. Porém, o aporte de cobre, proveniente da alteração de fases cupríferas dos horizontes sobrejacentes, permite a estabilidade da crisocola que se desenvolve às custas dos produtos argilomorfos.

\begin{tabular}{|l|ccc|}
\hline & SULFETOS & & MACIÇOS \\
\cline { 2 - 4 } & 1 & 2 & 3 \\
\hline ZONA DE CEMEN./OXID. & 37,37 & 24,26 & $-39,00$ \\
BOLSÕES DE SULFETOS & 39,78 & 39,78 & - \\
\hline
\end{tabular}

TABELA 4 - Balanço geoquímico do cobre nos produtos de alteração dos sulfetos de Santa Blandina: 1 = teor em $\mathrm{CuO}$ em $\%$ peso; $2=$ teor em $\mathrm{CuO}$ em g por $100 \mathrm{~g}$ do material sulfetado; $3=\%$ de perda em relação ao material sulfetado.

\begin{tabular}{|l|cc|}
\hline & ESCARNITO & GRANATIFERO \\
\hline & 1 & 2 \\
\hline CONJUNTO IIb & 23,07 & 13,08 \\
CONJUNTO IIa & 11,95 & 8 \\
CONJUNTO Ib & 5 & 10,8 \\
CONJUNTO Ia & 3,96 & 10,1 \\
ROCHA FRESCA & - & - \\
\hline
\end{tabular}

TABELA 5 - Teores em cobre nas diversas fácies de alteração do escarnito granatífero de Santa Blandina: 1 = teor em $\mathrm{CuO}$ em $\%$ peso; 2 $=$ teor em $\mathrm{CuO}$ em g por $100 \mathrm{~cm}^{3}$ do material do horizonte. Conjunto Ia: rocha com alteração incipiente; Conjunto Ib: rocha alterada; Conjunto IIa: alterita porosa; Conjunto IIb: alterita porosa lixiviada.

\begin{tabular}{|c|c|c|c|}
\hline & $\begin{array}{c}\text { ARGILOMORFO } \\
\text { CONJUNTO I }\end{array}$ & $\begin{array}{c}\text { ARGILOMORFO } \\
\text { CONJUNTO II }\end{array}$ & CRISOCOLA \\
\hline \%CuO & 15,56 & 29,13 & 43,64 \\
\%CRISOCOLA & 36 & 67 & 100 \\
\% ARGILA & 64 & 33 & - \\
\hline
\end{tabular}

TABELA 6 - Composição mineralógica dos produtos de acumulação calculada em função de seus respectivos teores em $\mathrm{CuO}$ (Santa Blandina). Conjunto I: rochas alteradas; Conjunto II: alteritas.

\section{DISCUSSÃO E CONCLUSÃO}

Os estudos realizados mostram claramente que a fixação do cobre nos perfis de alteração depende, essencialmente, da natureza e da quan- 
tidade das fases supérgenas que se formam e, por conseqüência, da natureza das soluções de alteração ( $\mathrm{pH}$, concentrações em $\mathrm{Cu}, \mathrm{Si}$....)

Em Santa Blandina, a alteração de sulfetos maciços libera importantes quantidades de cobre e promove, sem dúvida alguma, a formação de soluções de alteração concentradas neste elemento. Por outro lado, a dissolução da lente de mármore favorece, nas soluções de alteração, a ocorrência de $\mathrm{pH}$ pouco ácido (valores entre 5,8 e 7,5 foram encontrados no local). Tal $\mathrm{pH}$ favorece a imobilização do cobre sob a forma de carbonatos, silicatos ou óxidos (SERKIES et al., 1966; WOODS \& GARRELS, 1985, 1986). DECARREAU (1983) mostra que - no decorrer de experiências de sínteses de esmectitas cupríferas, desde que a relação molar $\mathrm{Cu} /(\mathrm{Cu}+\mathrm{Mg})$ seja superior a $0,5-o$ cobre se precipita sob a forma de crisocola, não mais entrando na estrutura do filossilicato.

Na base do perfil de alteração, nas zonas onde a drenagem é lenta, as concentrações em cobre e o pH devem ser suficientemente elevados para que o cobre possa se associar à sílica, liberada pela alteração do quartzo e das granadas. Forma-se então crisocola, que representa a principal fase cuprífera de origem supérgena.

Neste contexto particular, o cobre se acumula na base do perfil de alteração.

Oposto a este exemplo, a mineralização da Chapada Grande é disseminada, com baixos teores em cobre, o que deve certamente promover a existência de baixas concentrações em cobre nas soluções de alteração. Nos horizontes de alteração a goethita é a principal fase fixadora de cobre, enquanto que a caolinita aparece como fase de fixação apenas na couraça. A capacidade da goethita fixar cobre é limitada e além do mais este mineral é pouco abundante, representando menos de $15 \%$ da couraça.

Portanto, em Chapada Grande o cobre é lixiviado, o que aliás representa o caso mais freqüentemente encontrado nas alterações lateríticas.

Em Salobo 3A, os planos de xistosidade subverticais e perpendiculares à direção da vertente topográfica tendem a frear a drenagem lateral. Por outro lado a colmatação da porosidade pelas esmectitas de uma precedente fase de alteração (TOLEDO-GROKE, 1986; TOLEDOGROKE et al., 1989) acentua o confinamento, diminuindo igualmente a drenagem vertical. Esta estrutura particular, associada à existência, na rocha fresca, de teores em cobre mais elevados do que na mineralização de Chapada, levam certamente à formação de soluções com concentrações em cobre mais altas. Entretanto, elas per- manecem mais fracas que as de Santa Blandina, o que faz com que a formação de minerais específicos de cobre seja excepcional. Assim, a interação da estrutura geológica e da mineralogia (abundância de biotita e de minerais ferríferos) permite a formação de quantidades importantes de fases secundárias susceptíveis de fixarem cobre: interestratificados biotita-vermiculita, vermiculitas e goethitas.

Portanto, neste contexto, o cobre é globalmente retido nas alteritas com estruturas da rocha original conservadas. Esta jazida mostra que, em meio laterítico, em um contexto mineralógico e estrutural particular, os horizontes de alteração representam um minério potencial estimado em 10 milhões de toneladas a $0,77 \%$ em Cu. Tais concentrações não são portanto privilégio de regiões áridas (norte do Chile) ou de meios carbonatados (Congo, Zaire, Santa Blandina).

Como conseqüência prática deste estudo, percebe-se que nos materiais de superfície que são amostrados para a prospecção geoquímica duas situações podem se apresentar:

- em Santa Blandina, em meio carbonatado, os teores em $\mathrm{CuO}$ dos solos são elevados (1 a 5\%). O essencial do cobre encontra-se ainda sob a forma de finas partículas de crisocola $(<0,5 \mu \mathrm{m})$ intimamente associada aos minerais argilosos. As frações $<2 \mu \mathrm{m}$ apresentam teores em $\mathrm{CuO}$ três a quatro vezes superiores àqueles do solo total;

- em Chapada Grande, assim como em Salobo 3A, foi mostrado, o que aliás tem sido admitido por numerosos autores (ZEEGERS \& LEPRUN, 1979; SMITH \& PERDIX, 1984; WILHELM et al., 1978; WARNANT et al., 1981), que os óxidos de ferro e em particular as goethitas são as fases que, até a superfície, melhor conservam a memória de uma eventual mineralização cuprífera. Realmente, a associação do cobre com as caolinitas em Chapada e com as vermiculitas em Salobo 3A parece estar ligada a fenômenos puramente locais, onde esses filossilicatos, para poderem ser utilizados como guia de prospecção, devem ter sido formados simultaneamente com a liberação do cobre de sua fase portadora.

\section{AGRADECIMENTOS}

Os autores expressam seus sinceros agradecimentos às entidades e pessoas que, de maneiras diversas, permitiram a realização deste trabalho: FAPESP, CNPq, ATP Latérite (INSU/ORSTOM), DOCEGEO, Companhia Serra do Sul, Dr. João Baptista de Almeida Prado (proprietário da Mina de Santa Blandina) e A. Decarreau (Professor da Universidade de Poitiers). 


\section{REFERÊNCIAS BIBLIOGRÁFICAS}

BANKS, N.G. - 1974 - Distribution of copper in biotite and biotite alteration products in intrusive rocks near two Arizona porphyry copper deposits. Journal Research United States Geological Survey, Washington, 2(2): 195-211.

BASSET, W.A - 1958 - Copper vermiculite from northern Rhodesia. The American Mineralogist, Washington, 43(11/12): 1112-1133.

BRAUN, O.P.G. - 1970 - Contribuição à geomorfologia do Brasil Central. Revista Brasileira de Geografia, Rio de Janeiro, 32(3):3-39.

CHAFFE, M.A. - 1975 - Geology and resources of copper deposits: geochemical exploration techniques applicable in the search for copper deposits. Washington, United States Geological Survey. (Professional paper, 907-B).

CREACH, M. - 1988 - Accumulation supergène de cuivre en milieu latéritique: étude pétrologique, cristallochimique et géochimique de l'altération du skarn de Santa Blandina (Itapeva, Brésil). Université de Poitiers. 128p. (Thèse de Doctorat).

; DECARREAU, A.; NAHON, D. 1990 - Copper distribution in silicated weathering products of Santa Blandina skarn. (Itapeva, Brazil). Clays and Clay Minerals (no prelo).

DAVY, R. - 1979 - A study of laterite profiles in relation to bed rock in the darking range near Perth, W.A. Ca n berra, Geological Survey of Western Australia. (Report, 8).

DECARREAU, A. - 1983 - Etude expérimentale de la cristallogenèse des smectites: mesures des coefficients de partage smectite trioctaédrique-solution aqueuse pour les métaux $\mathrm{M}^{2+}$ de la première série de transition. Sciences Géologiques, Strasbourg. 185p. (Mémoire, 74).

DE ENDREDY, A.S. - 1963 - Estimation of free iron oxides in soils and clays by photolytic method. Clay Minerals Bulletin, London, (29):209-217.

FUCK, R.A. \& MARINI, O.J. - 1979 - O Grupo Araxá e unidades homotaxiais. IN: SIMPÓSIO SOBRE O CRÁTON DO SÃO FRANCISCO E SUAS FAIXAS MARGINAIS, 10., Salvador, 1979. Anais. Salvador, Sociedade Brasileira de Geologia, Núcleo da Bahia. p. 118-130.

GASTUCHE VAN OOSTERWYCK, M.C. 1970 - La structure de la chrysocolle. Compte Rendus, Academie Sciences, Paris, série D, (271):1837-1840.
GASTUCHE VAN OOSTERWYCK, M.C. 1977 - Sur les processus de silicification des calcaires dans le milieu supergène avec mention au processus de génèse des silicates de cuivre. Bulletin de la Societé Belge de Géologie, Bruxelles, 86(1/2):67-90.

GOVETT, G.J.S. - 1987 - Exploration geochemistry in some low-latitude areas: problems and techniques. Transactions of the Institution of Mining and Metallurgy, London, (96B):97-116.

HARSH, J.B. \& DONER, H.E. - 1984 - Specific adsorption of copper on a hydroxyaluminium-montmorillonite complex. Soil Science Society American Journal, Washington, 48(5): 1034-1039.

ILDEFONSE, P.; MANCEAU, A.; PROST, D.; TOLEDO-GROKE, M.C. - $1986-$ Hidroxy-Cu vermiculite formed by the weathearing of Fe-biotites at Salobo 3A, Carajas, Brazil. Clays and Clay Minerals, Lawrence, Kansas, 34(3):338-345.

KOUD, J.M. - 1985 - Pétrologie, minéralogie, métallogenie et géochimie des gîtes de cuivre de Niari au Congo. Strasbourg, Université. $174 \mathrm{p}$. (Thèse de $3^{\text {ème }}$ Cycle).

LAVILLE-TIMSIT, L.; LELEU, M.; WILHELM, E. - 1976 - Note préliminaire sur le comportement des éléments $\mathrm{Cu}, \mathrm{Pb}$, $\mathrm{Zn}, \mathrm{Ag}, \mathrm{Mn}, \mathrm{As}, \mathrm{Bi}$ lors de l'altération supergène d'une minéralization sulfurée. Bulletin de la Societé Geologique de France, Paris, 18(1):101-105.

LEARNED, R.E.; CHAO, T.T.; SANZOLONE, R.F. - 1981 - The partitioning of copper among selected phases of geologic media of two porphyry copper districts, Puerto Rico. Journal Geochemical Exploration, Amsterdan, 15(1-3):563-581.

McBRIDE, M.B. - 1976- Hydratation structure of exchangeable $\mathrm{Cu}^{2+}$ in vermiculite and smectite. Clays and Clay Minerals, Lawrence, Kansas, 24(2):211-212.

McLAREN, R.G.; WILLIANS, J.G.; SWIFT, R.S. - 1983 - The adsorption of copper by soil samples from Scotland at low equilibrium solution concentrations. Geoderma, Amsterdan, 31(1):97-106.

MOSSER, C.; MESTDAGH, M.; DECARREAU, A.; HERBILLON, A. - 1989 Spectroscopic (ESR, EXAFS) evidence of $\mathrm{Cu}$ for (Al-Mg) substitution in octahedral layers of smectites. IX Int. Clay Conf., Strasbourg (no prelo).

\& ZEEGERS, H. - 1988 - The mineralogy and geochemistry of two copperrich weathering profiles in Burkina Faso, West Africa. Journal Geochemical Exploration, Amsterdan, 30(1-3):145-166. 
NEWBERG, D.W. - 1967 - Geochemical implications of chrysocolla bearing alluvial gravel. Economic Geology, Lancaster, PA., 62(7):932-956.

NICKEL, E.H. - 1982 - Secondary minerals from the oxidized zone of the teutonic bore sulphide deposit. Australian Mineral Industry, Victoria, 40(2):219-223.

-1984 - The mineralogy and geochemistry of weathering profile of the teutonic bore $\mathrm{Cu}-\mathrm{Pb}-\mathrm{Zn}-\mathrm{Ag}$ sulphide deposit. Journal Geochemical Exploration, Amsterdan, 22(1-3):239-264.

NOTEBAART, C.W. - 1978 - Cupriferous micas from the Chingola area: Zambia copperbelt. Transactions of the Institution of Mining and Metallurgy, London, (87B):74-78.

NOWLAN, G.A. - 1976 - Concretionary manganese-iron oxides in streams and their usefulness as a sample medium for geochemical prospecting. Journal Geochemical Exploration, Amsterdan, 6(1-3):193-210.

PARISOT, J.C. - 1989 - L'altération latéritique de protores cupriferes au Brésil. Paris, Université de Poitiers. 177p. (Thèse de Doctorat).

; DELVIGNE, J.; TOLEDO-GROKE, M.C. - 1983 - Petrological aspects of the supergene weathering of garnet in Serra dos Carajás (Pará, Brazil). IN: PÉTROLOGIE DES ALTÉRATIONS ET DES SOLS. D. Nahon \& Y. Noack (ed.). Sciences geologiques mémoire, Paris, (72):141-148.

SANTOS, B.A. - 1980 - Geologia e potencial mineral da região dos Carajás. IN: SIMPÓSIO SOBRE A PROVÍNCIA MINERAL DA SERRA DOS CARAJÁS, 1\%, Rio de Janeiro, 1980.

SERKIES, J.; LETOWSKY, F.; NIEMIEC, J. - 1966 - Application of the potential $\mathrm{pH}$ diagrams to characteristics of some zechstein copper deposits. Economic Geology, Lancaster, PA., 61(8):1266-1271.

SILLITOE, R.H. \& CLARK, A.H. - $1969-$ Copper iron sulfides as the initial products of supergene oxidation: Copiago mining district, Northern Chili. American Mineralogist, Washington, 54(12): 1684-1700.

SMITH, R.E. \& PERDIX, J.L. - 1985 - Pisolitic laterite geochemistry in the Golden Grove massive sulphide district, Western Australia. Journal Geochemical Exploration, Amsterdan, 18(1-3):131-164.
THORNBER, M.R. - 1979 - Supergene alteration of sulphides: V-Laboratory studies on the dispersion of $\mathrm{Ni}, \mathrm{Cu}, \mathrm{Co}$ and $\mathrm{Fe}$. Chemical Geology, Amsterdan, 26(1):135-149. -1985 - Supergene alteration of sulphides: VII-Distribution of elements during Gossan - Forming Process. Chemical Geology, Amsterdan, 53(2):279-301.

TOLEDO-GROKE, M.C. - 1986 - Intemperismo das rochas mineralizadas em cobre de Salobo 3A, serra dos Carajás: mecanismos de alteração dos minerais primários e localização do cobre nos produtos secundários. São Paulo, Instituto de Geociências, USP. 173p. (Tese de Doutoramento).

; PROST, D.; ILDEFONSE, P.; MELFI, A.J.; DELVIGNE, J.; PARISOT, J.C. - 1985 - Alteração dos minerais na zona supérgena da formação cuprífera do Salobo 3A (serra dos Carajás): localização do cobre nos produtos secundários. Revista Brasileira de Geociências, São Paulo, 15(4):293-299.

; BOULANGE, B.; PARISOT, J.C.; MELFI, A.J. - 1989 - Altération des biotites dans les roches cupriferes de Salobo 3A, serra dos Carajás (Brésil) - I - Formation des phyllosilicates secondaires. Géodynamique, 4(2):135-150.

VEIGA, M.M. \& SCHORSCHER, H.D. 1982 - Caracterização tecnológica da relação cobre-óxidos hidratados de ferro no minério "oxidado" de Carajás, Marabá, PA, Brasil. IN: ENCONTRO DO HEMISFÉRIO SUL SOBRE TECNOLOGIA MINERAL, 1․, 1982. p.606-613.

WARNANT. F.; MARTIN, H.; HERBILLON, A.J. - 1981 - Kinetics of the selective extraction of iron oxides in geochemical samples: association between $\mathrm{Fe}$ and $\mathrm{Cu}$ in acid brown soils. J. Geochemical Exploration, Amsterdan, 15(1-3):635-644.

WILHELM, E.; LAVILLE-TIMSIT, L.; LELEU, M.; CACHAU-HERREILLAT, F.: CAPDECOMME, H. - 1978 - Behaviour of base metals around ore deposits: application to geochemical prospecting in temperate climates. IN: PROCEEDINGS OF INTERNATIONAL GEOCHEMICAL EXPLORATION, 7\%, Colorado, 1978. p.185-199.

WOODS, T.L. \& GARRELS, R.M. - $1985-$ Use of oxidized copper minerals as environ- 
mental indicators. Applied Geochemisty, Oxford, 1(1):181-187.

$$
\&+1986 \text { - Phase rela- }
$$

tions of some cupric hydroxyminerals. Economic Geology, Lancaster, PA., 81(8):1889-2007.
ZEEGERS, H. \& LEPRUN, J.C. - 1979 Évolution des concepts en altérologie tropicale et conséquences potentielles pour la prospection géochimique en Afrique occidentale soudano-sahélienne. Bulletin BRGM, Paris, série II, 2(2):229-239.

Endereço dos autores:

- Jean-Claude Parisot - ORSTOM, UR IG, 213 rue LaFayette 75490 - Paris (França).

- Monique Creach - Université de Poitiers, Laboratoire de Pétrologie de la Surface, 40 Av. du Recteur Pineau, 86022, Poitiers (França).

- Adolpho José Melfi - Universidade de São Paulo, Departamento de Geofísica, IAG, C.P. 30627, 01051 - São Paulo (Brasil) e Université d'Aix Marseille III, Laboratoire de Geosciences des Environnements, 13397 - Marseille (França).

- Daniel Nahon - Université d'Aix Marseille III, Laboratoire de Geosciences des Environnements, Case 431, 13397, Marseille (França).

- Maria Cristina Toledo-Groke - Universidade de São Paulo, Departamento de Geologia Geral, IGc, C.P. 20899, 01498 - São Paulo (Brasil).

- Jean Jacques Trescases - Université de Poitiers, Laboratoire de Pétrologie de la Surface, 40 Av. du Recteur Pineau, 86022 - Poitiers (França). 